\title{
ADERÊNCIA À NORMA ISSAI 5300 DA INTOSAI NA FISCALIZAÇÃO DE TECNOLOGIA DA INFORMAÇÃO DOS TribunaIS DE CONTAS ESTADUAIS DO BRASIL
}

\author{
COMPLIANCE WITH INTOSAI ISSAI STANDARD 5300 \\ IN THE INFORMATION TECHNOLOGY INSPECTION OF \\ THE BRAZILIAN STATE COURTS OF AUDITORS
}

Reuben Bezerra Barbosa - reubenbb@gmail.com ${ }^{1}$ Érico Veras Marques - ericovmarques@gmail.com² Jocildo Figueiredo Correia Neto - jocildo@ufc.br ${ }^{3}$

Graduação em Ciência da Computação

pela Universidade de Fortaleza(2002), graduação em Direito pela Universidade de Fortaleza(2010),Mestre em Administração e Controladoria pela Universidade Federal do Ceará Orcid/Lattes: http://lattes. cnpq.br/2435459036028414 2 Graduação em Ciências Econômicas pela Universidade Federal do Ceará (1991), graduação em Informática pela Universidade de Fortaleza (1990). Doutor em administração de empresas (EAESP/FGV) Orcid/Lattes: https://orcid. org/000o-0003-0011-6938 3

Graduação em Ciências da Computação pela Universidade Estadual do Ceará (1997), mestrado em Administração de Empresas pela Universidade de Fortaleza (2002). Doutor em administração de empresas (EAESP/FGV) Orcid/Lattes: https://orcid. org/0ooo-0003-0839-5804
RESUMO: A norma ISSAI 5300, desenvolvida pela Organização Internacional de Entidades Fiscalizadoras Superiores (INTOSAI), objetiva ser referência global sobre os fundamentos da auditoria de tecnologia da informação (TI). Assim, o trabalho analisa o cenário da fiscalização de TI nos tribunais de contas estaduais brasileiros quanto à aderência àquela norma. Para alcançar esse objetivo, identificaram-se as características estruturais e de recursos humanos, assim como os requisitos da norma com maior destaque positivo e maior destaque negativo nas unidades de fiscalização de TI dos tribunais. É uma pesquisa quantitativa que utilizou um questionário estruturado, aplicado junto a gestores e auditores dos tribunais, cujos resultados foram analisados por estatísticas descritivas. Os resultados apontaram que somente 8 (30,77\%) tribunais de contas estaduais possuem um setor para auditoria de TI. O requisito com maior destaque positivo foi "escopo da auditoria de TI" e com destaque negativo foi "planejamento anual da auditoria de TI". Conclui-se que a auditoria de TI nas cortes de contas estaduais ainda pode avançar, tanto na estruturação como na excelência do processo fiscalizatório. Trabalhos futuros podem ampliar a abrangência desta pesquisa, replicando a metodologia para investigar os mesmos requisitos da norma ISSAI 5300, aprofundando a análise em outros tribunais de contas estaduais, em tribunais de contas municipais ou, até mesmo, no tribunal de contas da união.

PAlaVras-Chave: Tribunal de contas estadual; Auditoria; Tecnologia da informação; Norma ISSAI 5300 INTOSAI.

AвSTRACт: The ISSAI 5300 standard, developed by the International Organization of Supreme Audit Institutions (INTOSAI), is intended to be a global reference on the fundamentals of information technology (IT) auditing. So, the present work analyzes the IT supervision scenario in the Brazilian State Courts of Auditors regarding adherence to that standard. To achieve this objective, it was necessary to identify the structural and human resources characteristics, as well as the requirements of the norm with the most positive highlight and most negative highlight in the IT enforcement units in those courts. This is a quantitative research, which used a structured questionnaire, applied to managers and auditors of the state courts of Brazil, using descriptive statistics to achieve the results. The survey results indicated that only $8(30.77 \%)$ state audit courts have a structured IT audit industry. The most prominent requirement was "IT audit scope" and the negatively highlighted requirement was "IT audit annual planning". It is concluded that the IT audit in the state courts can still advance, both in structuring and level 
of excellence of the entire inspection process. Future work may expand the scope of this research, replicating the methodology to investigate the same requirements of the ISSAI 5300 standard, deepening the analysis in other courts of state accounts, in courts of municipal accounts or even in the court of accounts of the union.

KEYWORDS: State court of auditors; Audit; Information technology; ISSAI 5300 INTOSAI Standard.

Data de Submissão: 10/01/2021

Data de Revisão: 10/01/2021

Data de Aceitação: 10/01/2021 


\section{INTRODUÇÃO}

Com a expansão do uso da informática pelo setor público, tornou-se notório o crescimento da modalidade de auditoria de informática ou de tecnologia da informação (TI), como é mais conhecida. Consiste no processo de coleta e avaliação de evidências para determinar se um sistema de computador foi projetado para manter a integridade dos dados, permitir que os objetivos organizacionais sejam efetivamente alcançados, identificando violações dos princípios de legalidade, eficiência e economia (MONTEIRO, 2008; ISMAIL; ABIDIN, 2009; INTOSAI, 2016).

De forma a auxiliar o aprimoramento do controle externo, entidades internacionais, como a Organização Internacional de Entidades Fiscalizadoras Superiores (INTOSAI), desenvolveram as normas internacionais de auditoria com o objetivo de estabelecer padrões técnicos e de comportamento. Com a adoção destas melhores práticas, a entidade fiscalizadora superior (EFS) pode atingir uma qualificação na condução dos trabalhos e a garantia de atuação suficiente e tecnicamente consistente do auditor e de sua opinião (TCU, 2017).

As normas internacionais de auditoria representam os requisitos básicos a serem apreciados no desenvolvimento do trabalho de auditoria. Tais normas devem ser percebidas como princípios e regras elaborados pelas entidades e organismos regulamentadores da área de controle e auditoria, que prescrevem orientações e diretrizes a serem observadas no desempenho da atividade fiscalizatória (TCU, 2017).

Reconhecida mundialmente, a INTOSAI expede padrões normativos de auditoria governamental, referendados pelos países-membro da Organização das Nações Unidas (ONU), incluindo o Brasil, representado pelo Tribunal de Contas da União (TCU). A INTOSAI possui status consultivo especial junto ao Conselho Econômico e Social (ECOSOC) das Nações Unidas (VALDELANDE, 2003; TCU, 2018).

O percurso para alcançar a excelência de qualidade no processo de auditoria está diretamente ligado à adoção e à adequada implementação dos mais elevados padrões internacionais aceitos, ou seja, as normas internacionais de auditoria da INTOSAI, mais conhecidas como ISSAIs, do inglês International Standards of Supreme Audit Institutions (AKYEL; ERKAN, 2012).

De fundamental relevância para essa pesquisa, destaca-se a norma ISSAI 5300, desenvolvida pelo Working Group on IT Audit (WGITA) da INTOSAI, formado por especialistas em tecnologia. Segundo consta em seu prefácio, o objetivo dessa norma é ser uma referência global sobre os fundamentos da auditoria de TI, abrangendo os princípios gerais, assim como a forma de abordagem e a metodologia para os trabalhos na área (INTOSAI, 2016).

Diante do exposto, pode-se destacar que as EFSs estão atuando cada vez mais na fiscalização dos gastos públicos investidos em segmentos específicos da administração pública, tais como a área de TI, 
obrigando os tribunais de contas a se especializarem e a se estruturarem de forma a viabilizar a fiscalização destes recursos.

Portanto, abre-se um campo de interesse para pesquisas acadêmicas acerca da situação da fiscalização de TI nos tribunais de contas estaduais (TCEs) do Brasil, sobretudo quanto à aderência à norma ISSAI 5300 da INTOSAI. Desta forma, a questão a ser respondida nessa pesquisa é: qual é o cenário do controle externo de tecnologia da informação nos tribunais de contas estaduais do Brasil quanto à aderência à norma ISSAI 5300 da INTOSAI?

Portanto, o objetivo central da pesquisa é analisar a situação do controle externo de TI nos tribunais de contas estaduais do Brasil quanto à aderência à norma ISSAI 5300 da INTOSAI.

Como objetivos específicos, a pesquisa objetivou identificar, nas unidades de fiscalização de tecnologia da informação nos tribunais de contas estaduais do Brasil, as características estruturais e de recursos humanos e os requisitos com maior destaque positivo e maior destaque negativo na análise da aderência das Cortes de Contas à norma ISSAI 5300 .

Este artigo está divido em cinco seções. Além dessa seção introdutória, a segunda seção apresenta o referencial teórico necessário à fundamentação da pesquisa. A terceira seção demonstra os procedimentos metodológicos adotados. Na sequência, apresentam-se os resultados, bem como a sua análise e discussão. A última seção contém as considerações finais, contribuições, limitações e oportunidades de estudos futuros.

\section{REFERENCIAL TEÓRICO}

No que tange à função fiscalizadora, o TCU (2011) acrescenta que a fiscalização é a forma de atuação pela qual são alocados recursos humanos e materiais voltados à avaliação da gestão dos recursos públicos, podendo ser feitas por iniciativa própria ou em decorrência de solicitação do Congresso Nacional.

As tecnologias de informação e comunicação (TIC) têm se difundido pelo setor governamental por meio do e-gov ou governo eletrônico, representado pela informatização de suas atividades internas e pela comunicação com o público externo, ou seja, os cidadãos, fornecedores, empresas, ou outros setores do governo e da sociedade (PINHO, 2008).

De acordo com Leão (2012), no setor público, a TI é especialmente relevante porque suporta decisões relativas a políticas públicas e aplicação de recursos públicos. Desta forma, são decisões que afetam diretamente a vida de muitas pessoas, quiçá de toda a sociedade. Nesse sentido, pode-se dizer que o uso da TI tem caráter estratégico para os governos.

Com a expansão do uso da informática pelo setor público, é instintivo o crescimento de uma nova modalidade de auditoria de cunho operacional. Trata-se da auditoria de informática, auditoria de sistemas 
de informação ou auditoria de tecnologia da informação, como é mais conhecida (MONTEIRO, 2008).

No entendimento da Organização Internacional de Entidades Fiscalizadoras Superiores (INTOSAI, 2016), auditoria de TI pode ser definida como um exame e revisão de sistemas de TI e controles relacionados para obter garantia ou identificar violações dos princípios de legalidade, eficiência, economia e eficácia do sistema de TI e controles relacionados.

Diante deste contexto, Hanashiro (2007) defende que a TI na administração pública precisa ser objeto de ações de controle, de forma a garantir que os critérios da informação sejam atendidos, contribuindo para a eficácia, eficiência e economicidade dos serviços públicos e para a prevenção de irregularidades, desvios e perdas de recursos.

A auditoria de TI é, portanto, um termo amplo que permeia as auditorias financeiras, auditorias de conformidade (avaliação de controles internos) e auditorias de desempenho, estas últimas buscando avaliar se os sistemas de TI atendem às necessidades dos usuários e não sujeitam a entidade a riscos desnecessários. No entanto, de acordo com INTOSAI (2016), pode haver casos em que algumas auditorias podem ser dedicadas apenas ao componente de TI de um sistema.

De forma a contribuir para que os tribunais de contas possam efetuar este controle externo na defesa dos princípios de boa governança, transparência e prestação de contas, respondendo às expectativas e às necessidades dos cidadãos, algumas entidades desenvolveram normas internacionais de auditoria.

Dentre as instituições internacionais, destaca-se a International Organization of Supreme Audit Institutions (Organização Internacional das Entidades Fiscalizadoras Superiores), conhecida como INTOSAI, que é uma organização internacional não governamental, autônoma, independente e não política. A entidade expede padrões normativos de auditoria governamental, referendados pelos países-membro da Organização das Nações Unidas (ONU), incluindo o Brasil, através do Tribunal de Contas da União (TCU).

A INTOSAI emitiu a norma ISSAI 5300, com o objetivo de ser um princípio global sobre os fundamentos da auditoria de TI. Ela congrega os princípios gerais, assim como a abordagem e a metodologia para realizar auditorias de TI (INTOSAI, 2016). A norma foi desenvolvida pelo Working Group on IT Audit (WGITA) da INTOSAI, um grupo de especialistas em tecnologia, tendo a Índia como líder e Brasil, Indonésia, Japão, Noruega, Polônia e EUA como membros (WGITA, 2016).

De acordo com INTOSAI (2016), esta norma pretende atuar como um guia para as EFS realizarem auditorias de TI, desenvolvendo sua capacidade em auditar e utilizar recursos limitados de auditoria de TI para fornecer uma garantia às entidades auditadas, ao governo e à sociedade sobre integridade, confiabilidade e valor para os recursos investidos em implementações de TI.

Por ser uma norma de nível específico, o material da ISSAI 5300 
foi dividido em duas categorias. A primeira são os requisitos, que são essenciais para a realização de uma auditoria de TI de boa qualidade. A segunda são as explicações, que apresentam e detalham os requisitos em termos mais gerais. Isso foi feito para garantir que a ISSAI mantenha sua principal função de fornecer orientação de apoio geral, conforme o framework ISSAI (INTOSAI, 2016).

\section{PROCEDIMENTOS METODOLÓGICOS}

O presente trabalho enquadra-se como descritivo. Quanto à abordagem da pesquisa, esta caracteriza-se como quantitativa. Os dados quantitativos foram obtidos a partir da aplicação de questionários estruturados, com perguntas fechadas para todos os respondentes. Eles foram preenchidos por meio de ambiente virtual (internet). Assim, os pesquisadores contataram os respondentes, disponibilizaram o questionário na internet e dirimiram eventuais dúvidas sobre as questões.

Vale ressaltar que, atualmente, no Brasil, existem 32 tribunais de contas divididos da seguinte forma: 1 (um) tribunal de contas da União (TCU), 26 (vinte e seis) tribunais de contas dos estados (TCE), 2 (dois) tribunais de contas dos municípios do estado (TCM), 2 (dois) tribunais de contas de município (TCM) e 1 (um) tribunal de contas do Distrito Federal (TC-DF).

Como forma a selecionar uma amostra homogênea, a partir da qual é possível inferir informações comparativas entre os membros da população, optou-se por considerar somente os tribunais de contas do tipo mais representativo em quantidade, ou seja, os tribunais de contas dos estados, acrescentando o tribunal de contas do Distrito Federal (TC-DF), dada a sua semelhança estrutural com os demais.

Sendo assim, a pesquisa pode ser caracterizada como um censo, uma vez que foram considerados os gestores responsáveis pela área de fiscalização de todos os tribunais de contas estaduais do Brasil, totalizando 27 unidades.

O alto nível técnico do assunto abordado no questionário, requerendo conhecimento especializado, associado à distância geográfica dos respondentes, assim como a dificuldade em compatibilizar as agendas, tiveram como consequência a viabilidade de inquirir um único gestor por tribunal de contas. Entretanto, tal limitação não invalida os resultados alcançados, tampouco as contribuições esperadas, já que os mesmos poderão servir de parâmetro de comparação para outros estudos.

O questionário estruturado foi composto por três blocos. No primeiro bloco, denominado "Dados de qualificação do respondente", procurou-se obter informações da qualificação do gestor. No segundo bloco, chamado "Dados estruturais da fiscalização de tecnologia da informação", havia perguntas com o objetivo de levantar informações estruturais das unidades de auditoria de TI. No terceiro e último bloco, nomeado "Requisitos da ISSAI 5300: diretrizes sobre auditoria de TI", 
constavam perguntas com o intuito de verificar a aderência às melhores práticas recomendadas pela norma da INTOSAI. Nesse terceiro bloco, foram apresentadas as afirmativas baseadas nos requisitos da norma ISSAI 5300, devendo o respondente optar por uma das opções de uma escala Likert baseada em cinco níveis: nível 1 = caso não concorde com o requisito (concorda em $0 \%$ ), nível 2 = caso concorde pouco com o requisito (concorda em $25 \%$ ), nível 3 = caso concorde mediano com requisito (concorda em 50\%), nível 4 = caso concorde muito com o requisito (concorda em $75 \%$ ) e nível 5 = caso concorde completamente com o requisito (concorda em 100\%).

A análise dos dados quantitativos foi feita mediante estatística descritiva, utilizando-se um peso (pontuação) para cada opção de resposta da escala Likert, possibilitando obter uma pontuação geral para cada tribunal de contas respondente. Tal metodologia permitiu uma análise comparativa entre as entidades, por meio de medidas de tendência central, tais como média, mediana e moda, assim como medidas de variabilidade, tais como desvio padrão, variância, valor máximo e mínimo.

O estudo dos dados coletados dos questionários permitiu levantar as características estruturais e de recursos humanos, identificar os requisitos com maior destaque positivo e maior destaque nos tribunais de contas de estado do Brasil.

\section{ANÁLISE DOS RESULTADOS}

A aplicação do questionário estruturado foi realizada no período de 21 de maio de 2018 a 6 de junho de 2018. Dentre os 27 tribunais de contas estaduais (TCEs) existentes no Brasil (incluído o tribunal de contas do Distrito Federal), 26 responderam ao questionário, totalizando $96,30 \%$ do total da amostra. Vale ressaltar que todos os 27 tribunais de contas foram contatados, seja por telefone ou por intermédio da ouvidoria do órgão.

Um dos aspectos fundamentais desta pesquisa foi identificar se os tribunais de contas estaduais do Brasil realizam a fiscalização de tecnologia da informação (TI) de forma estruturada e organizada em setor. Descobriu-se que somente 8 $(30,77 \%)$ dos TCEs possuem um setor estruturado para auditoria de TI.

Foi constatado que a região nordeste é a que possui o maior número de TCEs com o setor estruturado para auditar TI, totalizando 4 TCEs, ou seja, $50 \%$ do total. Foram identificados os seguintes estados para a região: Bahia, Ceará, Pernambuco e Piauí. A região sudeste apresenta-se logo em seguida com 2 TCEs, respectivamente nos estados de Espírito Santo e Rio de Janeiro. Finalmente, a região norte somente com o estado do Amazonas, e o Distrito Federal com o seu tribunal de contas.

Na Tabela 1, consta de forma consolidada o mapeamento da estrutura dos TCEs, apresentando o percentual para cada item em relação ao total de instituições que possuem o setor de auditoria de TI, assim como em relação ao universo das instituições. 
Tabela 1 - Informações consolidadas da estrutura dos TCEs.

\begin{tabular}{|c|c|c|c|}
\hline Questão / Resposta & Quantidade de TCEs & $\begin{array}{c}\text { Percentual frente aos TCEs c/ } \\
\text { auditoria de TI } \\
\text { (8 TCEs) }\end{array}$ & $\begin{array}{l}\text { Percentual frente ao todo } \\
\text { (26 TCEs) }\end{array}$ \\
\hline \multicolumn{4}{|c|}{ Tempo em que o TCE realiza auditoria de TI } \\
\hline Mais de 8 anos & 5 & $62,50 \%$ & $19,23 \%$ \\
\hline Mais de 5 até 8 anos & 2 & $25,00 \%$ & $7,69 \%$ \\
\hline Mais de 1 até 3 anos & 1 & $12,50 \%$ & $3,85 \%$ \\
\hline \multicolumn{4}{|c|}{ Setor de auditoria de TI é exclusivo para esta finalidade } \\
\hline Exclusivo & 5 & $62,50 \%$ & $19,23 \%$ \\
\hline Não exclusivo & 3 & $37,50 \%$ & $11,54 \%$ \\
\hline \multicolumn{4}{|c|}{ Existência de manual de auditoria de TI } \\
\hline Não possui manual & 5 & $62,50 \%$ & $19,23 \%$ \\
\hline Possui manual & 3 & $37,50 \%$ & $11,54 \%$ \\
\hline \multicolumn{4}{|c|}{ Setor de fiscalização de TI formalmente estabelecido } \\
\hline Setor formalmente estabelecido & 8 & $100,00 \%$ & $30,77 \%$ \\
\hline \multicolumn{4}{|c|}{ Nomenclatura utilizada para o setor de auditoria de TI } \\
\hline Gerência & 3 & $37,50 \%$ & $11,54 \%$ \\
\hline Núcleo & 3 & $37,50 \%$ & $11,54 \%$ \\
\hline Diretoria & 2 & $25,00 \%$ & $7,69 \%$ \\
\hline \multicolumn{4}{|c|}{ Cargo efetivo de analista/auditor de controle externo de TI } \\
\hline Possui o cargo & 4 & $50,00 \%$ & $15,38 \%$ \\
\hline Não possui o cargo & 4 & $50,00 \%$ & $15,38 \%$ \\
\hline \multicolumn{4}{|c|}{ Quantidade de analistas/auditores no setor de auditoria de TI } \\
\hline De 3 a 5 & 6 & $75,00 \%$ & $23,08 \%$ \\
\hline De 1 a 2 & 1 & $12,50 \%$ & $3,85 \%$ \\
\hline De 6 a 10 & 1 & $12,50 \%$ & $3,85 \%$ \\
\hline
\end{tabular}




\begin{tabular}{|c|c|c|c|}
\hline \multicolumn{4}{|c|}{ Nível de conhecimento em relação à norma ISSAI 5300} \\
\hline Já havia tomado conhecimento & 4 & $50,00 \%$ & $15,38 \%$ \\
\hline Não havia tomado conhecimento & 3 & $37,50 \%$ & $11,54 \%$ \\
\hline Procura seguir informalmente & 1 & $12,50 \%$ & $3,85 \%$ \\
\hline
\end{tabular}

FONTE: Elaborado pelos autores.

A Tabela 1 demonstra que, ao levar em consideração o total de 26 TCEs, podem-se inferir números ainda mais interessantes, considerando que somente $30,77 \%$ das cortes de contas possuem o setor de auditoria de TI de forma estruturada. Portanto, este seria o percentual máximo alcançado em cada item.

Pode-se observar que $5(62,5 \%)$ dos TCEs que realizam auditoria de TI de forma estruturada desempenham esta atividade há mais de 8 anos. Outros 2 (25\%) realizam a função entre de 5 e 8 anos e um (12,5\%), entre de 1 e 3 anos. Assim, já se tem certa experiência acumulada em alguns TCEs, o que pode servir de modelo aos demais.

Em 5 (62,5\%) dos TCEs que realizam auditoria de TI de forma estruturada, este setor é destinado exclusivamente a esta finalidade. Os $3(37,5 \%)$ TCEs restantes afirmaram que o setor não é exclusivo, podendo atuar em outras áreas de fiscalização. Vale ressaltar que nos $8(100 \%)$ TCEs que realizam auditoria de TI de forma estruturada, este setor foi formalmente estabelecido mediante portaria, resolução ou outra publicação.

Pode-se observar que 5 (62,5\%) dos TCEs não possuem um manual específico para auditoria de TI. Somente 3 (37,5\%) delas admitiram possuir um manual específico formalmente estabelecido na instituição. Considerando a extensão dos aspectos legais e técnicos envolvidos nas auditorias de TI, ter manuais específicos representa importante instrumento de suporte às atividades dos auditores.

Percebeu-se que as nomenclaturas "gerência" e "núcleo" são as majoritariamente utilizadas, por 3 (37,5\%) instituições cada uma. O termo "diretoria" é o menos aplicado, ficando com 2 (25\%) ocorrências.

Pode-se observar uma situação bem dividida, em que 50\% dos TCEs possuem o cargo efetivo de analista/auditor de controle externo de TI e os outros $50 \%$ não dispõem.

Percebeu-se que 6 (75\%) TCEs possuem de 3 a 5 analistas/auditores de controle externo trabalhando com fiscalização de TI. Uma instituição afirmou ter de 1 a 2 auditores e outra informou ter de 6 a 10, representando 12,5\% cada uma.

Pode-se observar que 4 (50\%) TCEs já haviam tomado conhecimento da norma, 1 (12,5\%) procura segui-la informalmente e 3 (37,5\%) não haviam tomado conhecimento dela. Isso sugere a necessidade de divulgação mais efetiva da norma.

A seguir, passa-se à identificação dos requisitos com maior destaque positivo e maior destaque negativo na verifi- 
cação da aderência dos TCEs à norma ISSAI 5300 da INTOSAI. Os resultados são apresentados em categorias conforme consta na divisão proposta por INTOSAI (2016), a saber: "Requisitos gerais especificamente relativos à auditoria de TI", "Requisitos relacionados com o processo de auditoria de TI", “Técnicas e ferramentas de auditoria de TI" e "Relatórios". A Tabela 2, a seguir, apresenta os resultados da primeira categoria.

Tabela 2 - Análise dos requisitos gerais relativos à auditoria de TI.

\begin{tabular}{l|c|c|c|c|c|c|c|c|c|}
\hline \multicolumn{7}{c|}{ REQUISITOS GERAIS ESPECIFICAMENTE RELATIVOS À AUDITORIA DE TI } \\
\hline Tema da questão & $\mathbf{1}$ & $\mathbf{2}$ & $\mathbf{3}$ & $\mathbf{4}$ & $\mathbf{5}$ & Soma & Méd. & Mod. & DP \\
\hline $\begin{array}{l}\text { Q1. Abordagem baseada em } \\
\text { risco }\end{array}$ & 0 & 2 & 2 & 2 & 2 & 28 & 3,50 & 5 & 1,20 \\
\hline Q2. Materialidade & 0 & 0 & 1 & 4 & 3 & 34 & 4,25 & 4 & 0,71 \\
Q3. Documentação & 0 & 0 & 0 & 3 & 5 & 37 & 4,63 & 5 & 0,52 \\
\hline Q4. Competência & 0 & 1 & 1 & 3 & 3 & 32 & 4,00 & 5 & 1,07 \\
\hline Percentual geral & $\mathbf{0 , 0 0}$ & $\begin{array}{c}\mathbf{9 , 3 8} \\
(\mathbf{\%})\end{array}$ & $\begin{array}{c}\mathbf{1 2 , 5} \\
\mathbf{( \% )}\end{array}$ & $\begin{array}{c}37,5 \\
\mathbf{( \% )}\end{array}$ & $\begin{array}{c}\mathbf{4 0 , 6 3} \\
\mathbf{( \% )}\end{array}$ & & & & \\
\hline Média geral & & & & & & $\mathbf{3 2 , 7 5}$ & $\mathbf{4 , 0 9}$ & $\mathbf{4 , 7 5}$ & $\mathbf{0 , 8 7}$ \\
\hline
\end{tabular}

FONTE: Elaborado pelos autores.

Percebe-se, a partir do Tabela 2, que na categoria "Requisitos gerais especificamente relativos à auditoria de TI", os TCEs apresentaram um excelente resultado geral. Na média, as respostas ficaram na marca dos 32,75 pontos, de um total máximo alcançável de 40 pontos. Houve uma maior concentração de respostas no nível " 5 " (concordo em 100\%), com 40,63\% das respostas. O nível " 4 " (concordo em 75\%) representou 37,5\%, o nível "3" (concordo em 50\%) marcou 12,5\%, o nível "2" (concordo em 25\%) contou com 9,38\% e o nível "1" não apresentou nenhuma ocorrência.

Merece destaque positivo o requisito referente à "Documentação", na qual os TCEs atingiram 37 pontos, com 5 cortes de contas optando pelo nível " 5 ” (concordo em 100\%). Este resultado positivo sugere que os TCEs que possuem um setor de auditoria de TI preocupam-se com a manutenção da documentação completa e detalhada do processo de auditoria de TI e de seus resultados.

O requisito com pior desempenho nessa categoria foi o referente à "Abordagem baseada em risco". Apesar de ser o item com resultado mais baixo, ainda assim alcançou 28 pontos, com a média em 3,5. 
Pode-se concluir, portanto, que os TCEs não apresentaram um resultado ruim em relação às auditorias de TI serem conduzidas através de uma abordagem baseada em riscos identificados na entidade auditada. Entretanto, observa-se margem para melhorias na aderência ao requisito, o que pode ser objeto de verificação nos tribunais de contas.

A próxima categoria a ser apresentada é a "Requisitos relacionados com o processo de auditoria de $\mathrm{TI}^{\text {", }}$ conforme demonstrado na Tabela 3.

Tabela 3 - Análise dos requisitos relacionados com o processo de auditoria de TI.

\begin{tabular}{|c|c|c|c|c|c|c|c|c|c|}
\hline \multicolumn{9}{|c|}{ REQUISITOS RELACIONADOS COM O PROCESSO DE AUDITORIA DE TI } & \multirow[b]{2}{*}{ DP } \\
\hline Tema da questão & 1 & 2 & 3 & 4 & 5 & Soma & Méd. & Mod. & \\
\hline Q5. Planejando auditorias de TI & 0 & 1 & 3 & 2 & 2 & 29 & 3,63 & 3 & 1,06 \\
\hline $\begin{array}{l}\text { Q6. Planejamento estratégico de auditoria de } \\
\text { TI }\end{array}$ & 2 & 1 & 2 & 1 & 2 & 24 & 3,00 & 5 & 1,60 \\
\hline Q7. Planejamento anual da auditoria de TI & 3 & 1 & 0 & 3 & 1 & 22 & 2,75 & 4 & 1,67 \\
\hline $\begin{array}{l}\text { Q8. Planejamento de auditoria de TI no nível } \\
\text { da equipe para a auditoria selecionada }\end{array}$ & 0 & 3 & 1 & 4 & 0 & 25 & 3,13 & 4 & 0,99 \\
\hline $\begin{array}{l}\text { Q9. Selecionando amostra apropriada para } \\
\text { auditoria de TI }\end{array}$ & 2 & 0 & 5 & 0 & 1 & 22 & 2,75 & 3 & 1,28 \\
\hline Q10. Objetivos da auditoria TI & 1 & 0 & 1 & 3 & 3 & 31 & 3,88 & 5 & 1,36 \\
\hline Q11. Escopo da auditoria de TI & 0 & 0 & 1 & 0 & 7 & 38 & 4,75 & 5 & 0,71 \\
\hline $\begin{array}{l}\text { Q12. Capacidades de uma EFS para realizar } \\
\text { auditorias de TI }\end{array}$ & 0 & 2 & 0 & 3 & 3 & 31 & 3,88 & 5 & 1,25 \\
\hline Q13. Alocação de recursos & 0 & 1 & 1 & 4 & 2 & 31 & 3,88 & 4 & 0,99 \\
\hline Q14. Envolvendo recursos externos & 2 & 2 & 1 & 1 & 2 & 23 & 2,88 & 5 & 1,64 \\
\hline Q15. Envolvimento com entidade auditada & 0 & 2 & 1 & 0 & 5 & 32 & 4,00 & 5 & 1,41 \\
\hline Q16. Evidência da auditoria & 0 & 0 & 1 & 1 & 6 & 37 & 4,63 & 5 & 0,74 \\
\hline
\end{tabular}




\begin{tabular}{|c|c|c|c|c|c|c|c|c|c|}
\hline $\begin{array}{l}\text { Q17. Execução da auditoria - recolher provas } \\
\text { de auditoria }\end{array}$ & 0 & 0 & 1 & 2 & 5 & 36 & 4,50 & 5 & 0,76 \\
\hline Q18. Supervisão e revisão & 1 & 0 & 0 & 1 & 6 & 35 & 4,38 & 5 & 1,41 \\
\hline $\begin{array}{l}\text { Q19. Casos de fraude, corrupção e outras } \\
\text { irregularidades }\end{array}$ & 0 & 1 & 0 & 4 & 3 & 33 & 4,13 & 4 & 0,99 \\
\hline Q20. Limitações & 1 & 0 & 1 & 3 & 3 & 31 & 3,88 & 5 & 1,36 \\
\hline Q21. Acompanhamento & 1 & 0 & 3 & 2 & 2 & 28 & 3,50 & 3 & 1,31 \\
\hline Percentual geral & $\begin{array}{l}9,56 \\
(\%) \\
\end{array}$ & $\begin{array}{c}10,29 \\
(\%)\end{array}$ & $\begin{array}{c}16,18 \\
(\%)\end{array}$ & $\begin{array}{c}25,00 \\
(\%)\end{array}$ & $\begin{array}{c}38,97 \\
(\%)\end{array}$ & & & & \\
\hline Média geral & & & & & & 29,88 & 3,74 & 4,41 & 1,21 \\
\hline
\end{tabular}

FONTE: Elaborado pelos autores.

Percebe-se, por meio da Tabela 3, que, na categoria "Requisitos relacionados com o processo de auditoria de $\mathrm{TI}^{\text {", }}$ os TCEs apresentaram um bom resultado geral. Na média, as respostas ficaram na marca dos 29,88 pontos de um total máximo alcançável de 40 pontos. Houve maior concentração de respostas no nível “ 5 " (concordo em 100\%), com 38,97\% das respostas. O nível "4" (concordo em 75\%) representou 25,00\%, o nível "3" (concordo em 50\%) marcou 16,18\%, o nível "2" (concordo em $25 \%$ ) contou com 10,29\% e o nível " 1 " foi o menos expressivo com 9,56\%.

Merece destaque o requisito referente ao "escopo da auditoria", no qual os TCEs atingiram 38 pontos, com 7 cortes de contas optando pelo nível " 5 " (concordo em 100\%). Este dado demonstra que os TCEs que possuem um setor de auditoria de TI estão prestando a devida importância à determinação do escopo das auditorias durante a fase de planejamento, de forma a garantir a realização dos objetivos da auditoria.

Os requisitos com pior desempenho nesta categoria foram os referentes a "Planejamento anual da auditoria de TI" e "Amostra". Os itens alcançaram 22 pontos cada, com a média ficando em 2,75. Este dado sugere que os TCEs possuem nível de aderência abaixo da média geral $(3,74)$ quanto ao planejamento anual de auditoria de TI ser feito de acordo com o plano estratégico de auditoria de TI, assim como quanto à seleção de amostras apropriadas para as auditorias de TI.

A próxima categoria a ser analisada é a referente às "Técnicas e ferramentas de auditoria de TI", conforme demonstrado na Tabela 4, a seguir. 
Tabela 4 - Análise dos requisitos de técnicas e ferramentas de auditoria de TI.

\begin{tabular}{|l|c|c|c|c|c|c|c|c|c|}
\hline \multicolumn{10}{|c|}{ TÉCNICAS E FERRAMENTAS DE AUDITORIA DE TI } \\
\hline $\begin{array}{l}\text { Tema da } \\
\text { questão }\end{array}$ & $\mathbf{1}$ & $\mathbf{2}$ & $\mathbf{3}$ & $\mathbf{4}$ & $\mathbf{5}$ & Soma & Méd. & Mod. & DP \\
\hline Q22. Técnicas & 0 & 1 & 1 & 3 & 3 & 32 & 4,00 & 5 & 1,07 \\
$\begin{array}{l}\text { Q23. } \\
\text { Ferramentas }\end{array}$ & 0 & 2 & 0 & 5 & 1 & 29 & 3,63 & 4 & 1,06 \\
\hline $\begin{array}{l}\text { Percentual } \\
\text { geral }\end{array}$ & $\begin{array}{c}\mathbf{0 , 0 0} \\
\mathbf{( \% )}\end{array}$ & $\begin{array}{c}\mathbf{1 8 , 7 5} \\
\mathbf{( \% )}\end{array}$ & $\begin{array}{c}\mathbf{6 , 2 5} \\
\mathbf{( \% )}\end{array}$ & $\begin{array}{c}\mathbf{5 0 , 0 0} \\
\mathbf{( \% )}\end{array}$ & $\begin{array}{c}\mathbf{2 5 , 0 0} \\
\mathbf{( \% )}\end{array}$ & & & & \\
\hline Média geral & & & & & & $\mathbf{3 0 , 5 0}$ & $\mathbf{3 , 8 1}$ & $\mathbf{4 , 5 0}$ & $\mathbf{1 , 0 6}$ \\
\hline
\end{tabular}

FONTE: Elaborado pelos autores.

Nota-se, a partir da Tabela 4, que na categoria “Técnicas e ferramentas de auditoria de TI", os TCEs apresentaram bom resultado geral. Na média, as respostas ficaram na marca dos 30,5 pontos de um total máximo alcançável de 40 pontos. Houve maior concentração de respostas no nível "4" (concordo em 75\%), com 50\% das respostas. O nível " 5 " (concordo em $100 \%$ ) representou 25\%, o nível " 2 " (concordo em 25\%) marcou 18,75\%, o nível “3” (concordo em 50\%) contou com 6,25\% e o nível "1" não apresentou respostas.

Merece destaque o requisito referente às "Técnicas de auditoria de TI", em que os TCEs atingiram 32 pontos, com 3 cortes de contas optando pelo nível " 5 " (concordo em 100\%). Este dado sugere que os TCEs que possuem um setor de auditoria de TI estão prestando boa atenção à implementação de técnicas adequadas de auditoria de TI.

O requisito com pior desempenho nesta categoria foi o referente à "Ferramentas de auditoria de TI". Apesar de ser o item com resultado mais baixo, mesmo assim alcançou 29 pontos, com a média ficando em 3,63. Este dado demonstra que os TCEs que possuem um setor de auditoria de TI estão prestando um bom cuidado quanto à implantação e disponibilização de ferramentas de auditoria de TI adequadas.

A próxima categoria a ser apresentada é a referente aos “Relatórios”, conforme demonstrado na Tabela 5. 
Tabela 5 - Análise do requisito de relatórios.

\begin{tabular}{|l|c|c|c|c|c|c|c|c|c|}
\hline \multicolumn{10}{|c|}{ RELATÓRIOS } \\
\hline $\begin{array}{l}\text { Tema da } \\
\text { questão }\end{array}$ & $\mathbf{1}$ & $\mathbf{2}$ & $\mathbf{3}$ & $\mathbf{4}$ & $\mathbf{5}$ & Soma & Méd. & Mod. & DP \\
\hline Q24. Relatórios & 0 & 0 & 1 & 4 & 3 & 34 & 4,25 & 4 & 0,71 \\
\hline $\begin{array}{l}\text { Percentual } \\
\text { geral }\end{array}$ & $\begin{array}{c}\mathbf{0 , 0 0} \\
\mathbf{( \% )}\end{array}$ & $\begin{array}{c}\mathbf{0 , 0 0} \\
\mathbf{( \% )}\end{array}$ & $\begin{array}{c}\mathbf{1 2 , 5 0} \\
\mathbf{( \% )}\end{array}$ & $\begin{array}{c}\mathbf{5 0 , 0 0} \\
(\mathbf{\%})\end{array}$ & $\begin{array}{c}37,50 \\
(\%)\end{array}$ & & & & \\
\hline Média geral & & & & & & $\mathbf{3 4 , 0 0}$ & $\mathbf{4 , 2 5}$ & $\mathbf{4 , 0 0}$ & $\mathbf{0 , 7 1}$ \\
\hline
\end{tabular}

FONTE: Elaborado pelos autores.

Depreende-se, ao observar a Tabela 5, que, na categoria "Relatórios", os TCEs apresentaram um resultado geral bem expressivo, ficando a média geral acima dos resultados obtidos nas demais categorias. A soma das respostas ficou na marca dos 34 pontos de um total máximo alcançável de 40 pontos. Houve uma maior concentração de respostas no nível "4" (concordo em 75\%), com 50\% das respostas. O nível “5” (concordo em 100\%) representou 37,5\%, o nível "3" (concordo em $50 \%$ ) marcou $12,5 \%$, o nível "2" (concordo em 25\%) e o nível "1" não apresentaram respostas.

O requisito único referente aos "relatórios" merece destaque positivo, uma vez que os TCEs atingiram 34 pontos, com 3 delas optando pelo nível “5” (concordo em 100\%).

Este dado demonstra que os TCEs que possuem um setor de auditoria de TI estão prestando a devida atenção com relação aos relatórios de auditoria de TI refletirem os resultados do processo da auditoria.

De forma a identificar os requisitos com maior destaque positivo e maior destaque negativo na verificação da aderência dos TCEs à norma ISSAI 5300, os requisitos foram agrupados respectivamente na Tabela 6 e na Tabela 7 a seguir.

Tabela 6 - Requisitos com maior destaque positivo.

\begin{tabular}{|l|c|c|c|c|c|c|c|c|c|}
\hline \multicolumn{1}{|c|}{ REQUISITOS COM DESTAQUE POSITIVO } \\
\hline $\begin{array}{l}\text { Tema da questão } \\
\begin{array}{l}\text { Q11. Escopo da auditoria } \\
\text { de TI }\end{array}\end{array}$ & $\mathbf{1}$ & $\mathbf{2}$ & $\mathbf{3}$ & $\mathbf{4}$ & $\mathbf{5}$ & Soma & Méd. & Mod. & DP \\
\end{tabular}




\begin{tabular}{|l|c|c|c|c|c|c|c|c|c|}
\hline Q16. Evidência da auditoria & 0 & 0 & 1 & 1 & 6 & 37 & 4,63 & 5 & 0,74 \\
\hline Q3. Documentação & 0 & 0 & 0 & 3 & 5 & 37 & 4,63 & 5 & 0,52 \\
\hline Percentual geral & $\begin{array}{c}\mathbf{0 , 0} \\
\mathbf{( \% )}\end{array}$ & $\begin{array}{c}\mathbf{0 , 0 0} \\
\mathbf{( \% )}\end{array}$ & $\begin{array}{c}\mathbf{8 , 3 3} \\
\mathbf{( \% )}\end{array}$ & $\begin{array}{c}\mathbf{1 6 , 6 7} \\
\mathbf{( \% )}\end{array}$ & $\begin{array}{c}75, \mathbf{0 0} \\
\mathbf{( \% )}\end{array}$ & & & & \\
\hline Média geral & & & & & & 37,33 & $\mathbf{4 , 6 7}$ & $\mathbf{5 , 0 0}$ & $\mathbf{0 , 6 6}$ \\
\hline
\end{tabular}

FONTE: Elaborado pelos autores.

Constata-se, a partir do Tabela 6, que os requisitos com maior destaque positivo foram os referentes ao "Escopo da auditoria de TI", com 38 pontos, “Evidência da auditoria”, com 37 pontos, e “Documentação", com 37 pontos. Houve forte tendência para os níveis " 5 " (concordo em 100\%) com 75\% e "4" (concordo em 75\%) com 16,67\% das respostas dos TCEs.

Tabela 7 - Requisitos com maior destaque negativo.

\begin{tabular}{|c|c|c|c|c|c|c|c|c|c|}
\hline \multicolumn{10}{|c|}{ REQUISITOS COM DESTAQUE NEGATIVO } \\
\hline Tema da questão & 1 & 2 & 3 & 4 & 5 & Soma & Méd. & Mod. & DP \\
\hline Q7. Planejamento anual da auditoria de TI & 3 & 1 & 0 & 3 & 1 & 22 & 2,75 & 1 & 1,67 \\
\hline $\begin{array}{l}\text { Q9. Selecionando amostra apropriada para } \\
\text { auditoria de TI }\end{array}$ & 2 & 0 & 5 & 0 & 1 & 22 & 2,75 & 3 & 1,28 \\
\hline Q14. Envolvendo recursos externos & 2 & 2 & 1 & 1 & 2 & 23 & 2,88 & 1 & 1,64 \\
\hline Q6. Planejamento estratégico de auditoria de TI & 2 & 1 & 2 & 1 & 2 & 24 & 3,00 & 1 & 1,60 \\
\hline Percentual geral & $\begin{array}{c}28,13 \\
(\%)\end{array}$ & $\begin{array}{c}12,50 \\
(\%)\end{array}$ & $\begin{array}{c}25,00 \\
(\%)\end{array}$ & $\begin{array}{c}15,63 \\
(\%)\end{array}$ & $\begin{array}{c}18,75 \\
(\%)\end{array}$ & & & & \\
\hline Média geral & & & & & & 22,75 & 2,84 & 1,50 & 1,55 \\
\hline
\end{tabular}

FONTE: Elaborado pelos autores.

Percebe-se, a partir da Tabela 7, que os requisitos com maior destaque negativo foram os referentes ao "Planejamento anual da auditoria de TI" (22 pontos), "Selecionando amostra apropriada para auditoria de TI" (22 pontos), "Envolvendo recursos externos" (23 pontos) e "Planejamento estratégico de auditoria de TI" (24 pontos). Houve uma forte tendência para os níveis " 1 " (concordo em $0 \%$ ) com 28,13\% e “3” (concordo em 50\%) com 25,00\% das respostas dos TCEs. 


\section{CONSIDERAÇÕES FINAIS}

Este estudo apresentou uma investigação sobre o cenário do controle externo de tecnologia da informação (TI) nos Tribunais de Contas estaduais do Brasil (TCEs) quanto à aderência à norma ISSAI 5300 da INTOSAI (Organização Internacional de Entidades Fiscalizadoras Superiores). O objetivo do estudo foi identificar as características estruturais e de recursos humanos, assim como os requisitos da norma com maior destaque positivo e maior destaque negativo nas unidades de fiscalização de TI nos TCEs.

Descobriu-se que somente 8 (30,77\%) TCEs possuem um setor estruturado para auditoria de TI no Brasil. Constatou-se que houve uma tendência para a implantação deste setor especializado ocorrida até 8 anos antes desta pesquisa, uma vez que a maioria (62,5\%) dos TCEs o fizeram antes deste período.

Foi possível identificar que em $5(62,5 \%)$ TCEs que realizam auditoria de TI de forma estruturada, este setor é destinado exclusivamente para esta finalidade. Os $3(37,5 \%)$ TCEs restantes afirmaram que o setor não é exclusivo, podendo atuar em outras áreas de fiscalização.

Pode-se concluir que este número é positivo, uma vez que ficou constatado que a maioria (62,5\%) dos TCEs que realizam auditoria de TI de forma estruturada encaram esta área de fiscalização de forma relevante, reservando um setor exclusivo para esta finalidade.

Adicionalmente, foi identificado que 5 (62,5\%) TCEs não possuem um manual específico para auditoria de TI. Somente 3 (37,5\%) admitiram possuir um manual específico formalmente estabelecido na instituição.

Percebeu-se que a minoria dos TCEs se preocupou em formalizar os procedimentos e padrões de auditoria em um manual específico para a área de fiscalização de TI. Vale ressaltar que a existência de um manual de auditoria é uma boa prática importante.

Outro dado importante identificado foi que em todos os $8(100 \%)$ TCEs que realizam auditoria de TI de forma estruturada, este setor foi formalmente estabelecido por meio de portaria, resolução ou outra publicação.

Este fato demonstra o apoio da alta direção das entidades em criar e manter a área em funcionamento, uma vez que, formalizando-se o setor, o mesmo passa a "ser visto" e a "ter voz" em momentos de decisões estratégicas na instituição.

Quanto à nomenclatura do setor de auditoria de TI, identificou-se que os termos "Gerência" e "Núcleo" são os majoritariamente utilizados, por 3 (37,5\%) instituições cada um. O termo "Diretoria" é o menos aplicado, ficando com duas (25\%) ocorrências.

Pode-se concluir que o destaque oferecido para este tipo de setor dentro do organograma das instituições ainda não é muito expressivo, uma vez que a maioria das áreas está categorizada como "Gerência" e "Núcleo", que geralmente estão posicionadas mais abaixo na estrutura. 
Identificou-se, ainda, que $50 \%$ dos TCEs possuem o cargo efetivo de analista/auditor de controle externo de TI e os outros $50 \%$ não dispõem.

Este dado chamou a atenção, uma vez que metade dos TCEs que possuem uma área específica para executar fiscalização de TI não possuem em seu quadro funcional (nem mesmo a previsão no plano de cargos) o perfil de analista/auditor de TI, que seria o técnico comprovadamente capacitado para realizar este tipo de atividade.

Quanto à quantidade de analistas/auditores de TI, 6 (75\%) TCEs possuem de 3 a 5 auditores de controle externo trabalhando com fiscalização de TI. Uma instituição afirmou ter de 1 a 2 auditores e outra informou ter de 6 a 10, representando 12,5\% cada uma.

Pode-se concluir, portanto, que na maioria dos TCEs que possuem uma área específica para executar fiscalização de TI, esta área ainda é pequena em termos de quantidade de servidores efetivos.

Finalmente, quanto ao nível de conhecimento que o TCE tem em relação à norma ISSAI 5300, identificou-se que 4 (50\%) já haviam tomado conhecimento da norma, 3 (37,5\%) não havia tomado conhecimento e um $(12,5 \%)$ procura seguir a norma informalmente.

Estes dados demonstram que é baixo o número de cortes de contas que seguem a norma ISSAI 5300, mesmo que informalmente. Vale ressaltar que é expressiva a quantidade de instituições que admitiram não haver nem mesmo tomado conhecimento da existência da norma $(37,5 \%)$.

Identificou-se que os requisitos com maior destaque positivo foram os referentes ao "Escopo da auditoria de TI" (38 pontos), "Evidência da auditoria" (37 pontos) e "Documentação" (37 pontos). Houve uma forte tendência para os níveis " 5 " (concordo em 100\%) com 75\% e "4" (concordo em 75\%) com 16,67\% das respostas dos TCEs.

Este dado demonstra um nível de aderência elevado dos TCEs, com relação à determinação do escopo da auditoria de TI ser realizado durante a fase de planejamento, de forma a garantir a realização dos objetivos da auditoria.

Outro resultado positivo foi em relação à manutenção da documentação completa e detalhada do processo de auditoria de TI e de seus resultados, demonstrando que os TCEs estão preocupados em manter a documentação suficiente do processo de auditoria de TI e de seus resultados, de forma a garantir que qualquer auditor de TI experiente, que não tenha participado da auditoria, possa replicá-la.

Quanto aos requisitos com maior destaque negativo, identificou-se que foram os referentes ao "Planejamento anual da auditoria de TI" (22 pontos), "Selecionando amostra apropriada para auditoria de TI" (22 pontos), "Envolvendo recursos externos" (23 pontos) e "Planejamento estratégico de auditoria de TI" (24 pontos). Houve uma forte tendência para os níveis " 1 " (concordo em $0 \%$ ) com 28,13\% e " 3 " (concordo em $50 \%$ ) com $25,00 \%$ das respostas dos TCEs.

Este dado demonstra que os TCEs possuem um nível de aderên- 
cia abaixo da média quanto ao planejamento anual de auditoria de TI ser feito de acordo com o plano estratégico de auditoria de TI. Este fato pode prejudicar a seleção do objeto de TI ou da entidade a ser auditada.

Por fim, conclui-se que a auditoria de TI nos TCEs ainda pode avançar, tanto em termos de estruturação quanto no nível de excelência de todo o processo fiscalizatório. De forma a auxiliar este caminho em busca da melhoria da qualidade da fiscalização, as cortes de contas têm a seu favor as normas internacionais de auditoria, sobretudo a ISSAI 5300 da INTOSAI.

Trabalhos futuros podem ampliar a abrangência da pesquisa, replicando a metodologia para investigar os mesmos itens do questionário estruturado, aprofundando a análise em outros tribunais, tais como os tribunais de contas municipais ou, até mesmo, o tribunal de contas da União.

\section{REFERÊNCIAS}

AKYEL, R.; ERKAN, B. Achieving Success In Assimilation And Implementation Of The Issais. Cukurova University Social Sciences Institute Magazine, Turkey, v. 21, n. 3, p. 1-16, 2012.

HANASHIRO, M. Metodologia para desenvolvimento de Procedimentos e Planejamento de Auditorias de TI aplicada à Administração Pública Federal. 2007. 166 f. Dissertação (Mestrado) - Curso de Mestrado em Engenharia Elétrica. Faculdade de Tecnologia, Departamento de Engenharia Elétrica, Universidade de Brasília, Brasília, 2007.

INTOSAI. ISSAI 5300: Guidelines on IT Audit. 2016. Disponível em: <http://www.issai.org/en_us/site-issai/ issaiframework /4-auditing-guidelines.htm>, Acesso em: mar/2018.

ISMAIL, N. A.; ABIDIN, A. Z. Perception towards the importance and knowledge of information technology among auditors in Malaysia. Journal of Accounting and Taxation, v. 1, n. 4, p. 61, 2009.

LEÃO, P. A. S. Auditoria de Tecnologia da Informação - A experiência do TCE-CE. Revista Controle doutrinas e artigos, v. 10, n. 1, p. 141-168, 2012.

MONTEIRO, G. B. Auditoria de tecnologia da informação na administração pública no âmbito dos Municípios do Estado do Rio de Janeiro. 2008. Tese de Doutorado. 132 f. Tese (Doutorado) - Curso de Mestrado em Administração Pública. Escola Brasileira de Administração Pública e de Empresas. Fundação Getúlio Vargas, Rio de Janeiro, 2008.

PINHO, J. A. G. Investigando portais de governo eletrônico de 
estados no Brasil: muita tecnologia, pouca democracia. Revista da Administração Pública. Rio de Janeiro. Maio/Jun, 2008.

TCU - Tribunal de Contas da União. Auditoria

Governamental. Instituto Serzedello Corrêa, Brasília, 2011.

Funcionamento do TCU. 2017. Disponível em: <http:// portal2.tcu.gov.br/portal/page/portal/TCU/institucional/conheca_ tcu/institucional_funcionamento $>$. Acesso em: nov/2017.

. Relações internacionais: Organizações

Internacionais às quais o TCU integra. 2018. Disponível em: <http://portal.tcu.gov.br/relacoes-institucionais/ relacoes- internacionais/\#intosai>. Acesso em: abr/2018.

VALDELANDE, V. M. La Organización Internacional de Entidades Fiscalizadoras Superiores - INTOSAI. Auditoría Pública, n. 30, p. 86-94, 2003.

WGITA. Final report on Project 5: Development of ISSAI-5300 on 'Guidelines on IT Audits". 25th Meeting of the INTOSAI Working Group on IT Audit. Brazil, 2016. 